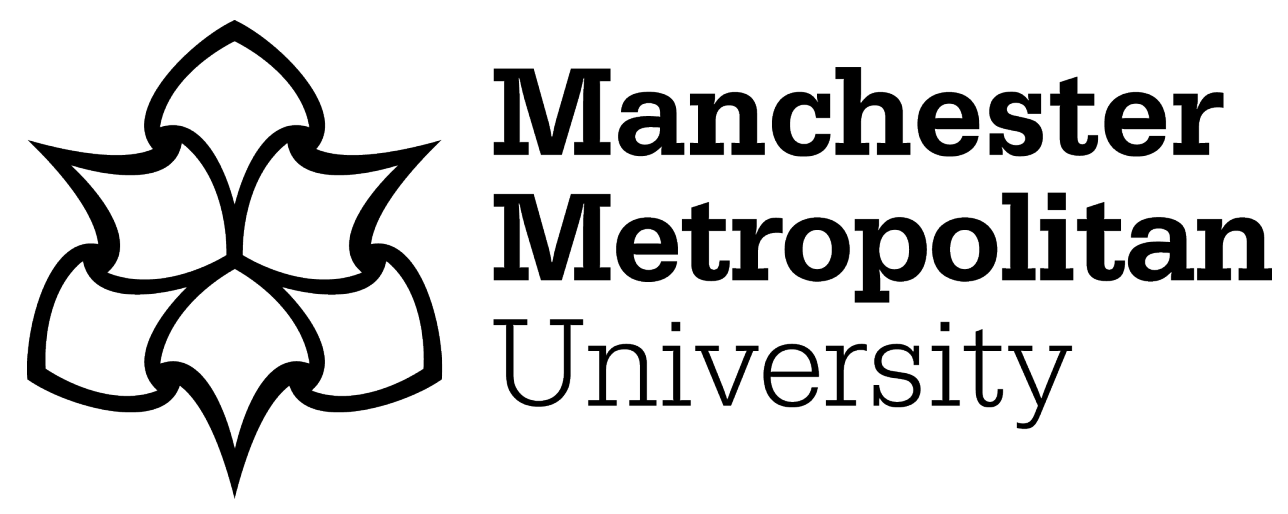

Skinner, HM ORCID logoORCID: https://orcid.org/0000-0002-6505-8073 and Melewar, TC (2018) Defining and delimiting the scope of the Corporate Identity construct. The Marketing Review, 18 (2). pp. 115-129. ISSN 1469-347X

Downloaded from: https://e-space.mmu.ac.uk/621232/

Version: Accepted Version

Publisher: Westburn Publishers

DOI: https://doi.org/10.1362/146934718X15333820910138

Please cite the published version 


\section{Defining and delimiting the scope of the Corporate Identity construct}

Professor TC Melewar

The Business School, Middlesex University, UK

E-mail: t.c.melewar@mdx.ac.uk

Dr Heather Skinner*, Institute of Place Management, Manchester Metropolitan University, UK E-mail: heatherskinnercorfu@gmail.com

[*Corresponding author]

T C Melewar is Professor of Marketing and Strategy at The Business School, Middlesex University London, UK. Prior to joining Middlesex in August 2013, he was Professor at Brunel University and Zurich University of Applied Sciences (ZHAW) in Switzerland. He also has held academic positions at University of Warwick (Warwick Business School) and De Montfort University in the UK and MARA Institute of Technology, Malaysia

Heather Skinner's main research interest is the representation of national identity through nation brands, and in particular the role the cultural output of a nation can play in economic regeneration. She has published papers on place marketing in Place Branding and Public Diplomacy, the Journal of Brand Management, and Journal of Marketing Management. 


\title{
Defining and delimiting the scope of the Corporate Identity construct
}

\begin{abstract}
This paper defines and delimits the scope of the Corporate Identity (CI) construct by exploring its applicability outside its usual research focus on large corporate entities. We also provide an important bridge between the management literature where the concept of Organisational Identity (OI) is better researched and understood, and the marketing literature where it is more common to find research defined in terms of CI. The conceptual underpinning of this paper favours a view of CI as a construct that is 'multi-modal and multi-sensory', therefore we use an all-encompassing definition of CI as the presentation of an organisation to every stakeholder. Moreover, research into CI and smaller entrepreneurial family-owned organisations is relatively underdeveloped, thus we based our findings on a conceptualisation of the seven broad dimensions of CI namely: Corporate Communication; Corporate Design; Corporate Culture; Behaviour; Corporate Structure; Industry Identity; and Corporate Strategy, as they relate to small family firms.
\end{abstract}

\section{Keywords:}

Corporate Identity; Organisational Identity; Image; SMEs; Brewing Industry; Family firms 


\section{INTRODUCTION}

Within the management literature, the terms "organisational identity / organisational image" are more commonly found than the terms "corporate identity / corporate image", which, especially linked to customer-related issues such as corporate "reputation" or "branding" (Walsh, Mitchell, Jackson \& Beatty, 2009) appear more prevalent in the marketing literature. There have been attempts made to clarify the management literature's understanding of the terms "organisational identity" as being primarily concerned with the organisation's members' shared meanings and awareness of belonging, and "corporate identity" as belonging to the institutional and customer domains, and primarily defined as 'the distinctive public image that a corporate entity communicates that structures people's engagement with it' (Cornelissen, Haslam \& Balmer, 2007, S3). However Oliver and Roos (2007) believe that a key underpinning issue regarding such definitional problems is in our understanding of the very construct of 'organisation'. Moreover, Cornelissen et al. (2007) also believe there remains a challenge for any research into these topics when considering both the practical and methodological issues of undertaking such study across such a wide range of bodies of literature.

The aim of this paper is therefore to address these gaps in knowledge firstly, through definition: conceptualising Corporate Identity (CI), a construct that is more commonly found in the marketing literature, and doing so in relation to the concept of Organisational Identity (OI), which is better researched and understood in management research; and secondly through delimiting the CI construct, exploring its applicability to SMEs rather than to the larger corporate entities that have hitherto tended to be the objects of CI enquiry. Thus addressing another gap in the literature that recognises, in the case particularly of smaller entrepreneurial family-owned 
organisations, research into these issues is relatively underdeveloped (Abimbola, 2001;

Abimbola \& Kocak, 2007; Lähdesmaäki \& Siltaoja, 2010).

\section{Organisational Identity and Image}

It has been proposed that the concept of OI operates at individual, organisational and relational levels (He \& Baruch, 2010). An organisation's identity defines both what it is, and what it is not. It is what makes an organisation distinctive (Albert \& Whetten, 1985; Dutton \& Dukerich, 1991). OI is central to the organisation, guiding the organisation and its members' activity (Dutton \& Dukerich, 1991) and is enduring over time (He \& Baruch, 2010). OI can be perceived in various ways: From a social actor perspective as sense-making; from a social constructivist perspective as sense-giving (He \& Baruch, 2010); or from a post-modern perspective that results in no distinction being made between the inside-out identity construct, or the outside-in image construct (Gioia, Schultz \& Corley, 2000). Organisational image can also be perceived as a major part of the OI creation process (He \& Baruch, 2010), and is also perceived as aligning to reputation. However, Lähdesmäki and Siltaoja (2010, p208) distinguish image as applying to stakeholder perceptions of the organisation, and reputation as relying more upon 'comparison and judgement'. These authors also identify a gap in the reputation literature with regard to SMEs where 'the owner-manager usually holds a key or unifying position in relation to the firm’s reputation' (Lähdesmäki \& Siltaoja, 2010, p209). However, whereas Otubanjo and Amujo (2012) propose that a deliberate attempt at creating a strong and positive CI is indeed undertaken by most firms, whether global, regional, national, or local, for many SMEs 'deliberate and coherent brand and reputation building strategies are regarded as something that is beyond available resources to implement' (Abimbola \& Kocak, 2007, p425). Furthermore, although CI is 
often proposed to be particularly created through branding, Cornelissen et al. (2007) believe that the concepts of OI and CI are becoming much less distinguishable. Oliver and Roos (2007), instead, believe that such definitional problems regarding OI rest mainly on the way the construct of "organisation" per se is perceived.

\section{Corporate Identity and Identification}

While CI has its historical roots in "preoccupations with visual design and logos ... integration of visual identity, corporate public relations and management communication messages ... [and] customer reactions to and identification with organizations', CI now tends to be as much concerned with the overall identity and 'general meaning of a corporate entity that resides in the values, beliefs, roles and behaviour of its members as well as in the shared symbols and other artefacts that they create' (Cornelissen et al., 2007, S1-S8). However, Bartholmé and Melewar (2009) that CI should retain a conceptualisation that includes all sensory elements, not only visual.

Walsh et al. (2009, p189) cite Brown et al. 's. (2006) attempt at distinguishing between four types of corporate associations, where CI is the identity held by its' members about the organisation; intended image is what the organisation aims to communicate externally; construed image is what 'organization members believe others outside the organization hold', and reputation 'refers to mental associations about the organization actually held by others outside the organization'. From this perspective, and linking with the literature on social identity, whether or not an individual identifies with an organisation will depend on whether they are within or outside of the organisation. Thus an organisation's members can be seen to be 
identifying with the organisation's identity, whereas those who were outside of an organisation would be identifying (or otherwise) with its reputation (Elsbach \& Bhattacharya, 2001), which also can be perceived as having a functional dimension (Otabanjo \& Chen, 2013).

Otubanjo and Amujo (2012) consider that CI encompasses the way the organisation's personality is appraised, conceptualised, and communicated to its stakeholders. Similar to many other discussions of CI within the marketing literature, these authors locate CI within the realm of promotion and communication, the way an organisations presents itself from the inside-out for the purposes of, for example: Differentiating an organisation from its competitors in an increasingly competitive global business environment; re-conceptualising the organisation following business consolidation; attracting customers and investors; increasing sales; and creating a favourable image among stakeholders, and when entering new markets. Practitioner conceptualisations of CI consider it also to stem from corporate image, and tend to focus on CI planning and management, including the management of corporate change (Otubanjo, 2008). Whereas informal $\mathrm{CI}$ is created not through a planned process by the organisation, but rather through the behaviours of the organisation's employees, particularly those in customer-facing roles in service organisations, and this may misalign with the $\mathrm{CI}$ intended to be communicated by the organisation (Otubanjo and Amujo, 2012).

Also from a social identity perspective, and in relation to the specific corporate form of franchise operations, Ullrich, Wieseke, Christ, Schulze and van Dick (2007, S32-S33) distinguish OI as referring to 'the franchisee's employees [and] the identities of the franchisee', and CI to the franchiser, a distinction that seems to relate the terms not only to the size of an organisation, but 
also to organisational ownership. However, a proposition that the term CI may not be applied to a large parent organisation with many subsidiaries and / or franchises, is one that we would certainly challenge. We also propose that CI research need not be restricted only to large global corporations, but may be applicable in all contexts of the corporate form regardless of size, including SMEs. As recognised by Veldman (2013, S18-S19), the corporate form is the 'dominant economic concept .... [which] can be understood as a reified and singular construct', although also stressing there is an opposing perspective where "the corporate form, is said to relate only to the agency of individual private actors'. In the case of SMEs, there are fewer individual private actors within the organisation, and the owner-manager tends to exert greater control on individual actions than in larger corporations.

The conceptual underpinning of this paper favours Burghausen and Balmer's (2014) view of CI as a construct that is 'multi-modal and multi-sensory', and inclusive of 'corporate design, corporate communication and corporate behavior'. In this respect, CI relates to the presentation of an organisation to every stakeholder. It is what makes an organisation unique and it incorporates the organisation's communication, design, culture, behaviour, structure, industry and strategy, and is thus intrinsically related to both the corporate personality and image (Melewar \& Karaosmanoglu, 2006). We believe that taking such a broad perspective, we will be able to better overcome the practical and methodological challenges identified by Cornelissen et al. $(2007, \mathrm{~S} 8)$ of researching these issues in a way that indeed does at 'attempt integration across social, organizational and corporate literatures'. 
We have chosen to contextualise our conceptualisation of CI with a family-run microbrewery located on a small Greek island, heavily reliant upon tourism markets in the summer, but also serving local and geographically near export markets to extend their sales throughout the winter months. Corfu Microbrewery focuses on producing only a 'natural living product', 'real ale', typical of the traditional brewing industry (Pitta \& Scherr, 2009) but with no preservatives, thus differentiating it from other microbreweries and also from the beers produced by larger global players. Thus we may also be able to address the question identified by Cornelissen et al. (2007, S10) as being of importance for future research into such matters 'of how the identities that underpin the patternings and products of organizational life are actually formed and constructed'. Burghausen and Balmer's (2014) research also addressed an identified gap in the CI research with regard to family-owned firms, although their research was contextualized to the Shepheard Neame brewery which is categorized as a medium-sized company, whereas our study focuses on the applicability of CI to small entrepreneurial organisations. Based on the broad perspective of CI identified in our critical review of the literature, the remainder of this paper will present this conceptualisation relating to the seven dimensions of CI identified by Melewar and Karaosmanoglu (2006), namely: Industry Identity; Corporate Culture (encompassing the corporate philosophy, values, mission, principles, guidelines, history, along with the founder, country of origin, and subcultures of the corporation); Corporate Strategy (examining both differentiation and positioning strategy); Corporate Structure (encompassing the brand and organisational structure); Corporate Design (encompassing the corporate visual identity system and its application); Behaviour (corporate, employee and management); and Corporate Communication (encompassing controlled, uncontrolled and indirect communication). 


\section{Industry identity}

Across Europe, family owned organisations are the 'most prevalent type of ... ownership category' (Hautz, Mayer \& Stadler, 2013, p106). These types of organisations tend to be more locally connected, more focused in their strategy, committed to long-term survival of the firm, less likely to separate organisational ownership from organisational control, having both family and non-family members in managerial positions (Harris \& Ogbonna, 2007), more likely than other firms to be "motivated by non-financial factors ... [and] more prone to adopt proactive stakeholder engagement ... activities ... [to] preserve and enhance their socioemotional wealth' (Cennamo, Berrone, Cruz \& Gomez-Mejia, 2012, p1153). Nikodemska-Wolowik (2006) also recognised the entrepreneurial nature of family businesses, and their ability to create strong associations with their locales, thus linking CI to the Country Of Origin (COO) of such organisations.

In the brewing industry where family owned firms are commonly found, such organisations are also 'adept at balancing entrepreneurship with professional management' (Geppert, Dörrenbächer, Gammelgaard \& Taplin, 2013, p319), something not always evidenced within family owned organisations in other industry sectors. Also, unlike European family-owned organisations in other industry sectors that can be less likely to diversify internationally (Hautz et al., 2013), brewers such as Heineken and Carlsberg only grew to their current positions of industry strength by being international from the outset (Geppert et al., 2013), although Calori, Johnson and Sarnin (1992, pp63-71) did select companies from the brewing industry for their study into strategic management by virtue of that industry's 'degrees of local specificity', and the 
difference in size of the industry's competitive players, which tend to be polarized 'between groups which have become, or are becoming, international, and small highly focused brewers'.

Beer is the second most consumed type of alcoholic beverage worldwide (World Health Organisation, 2014). As has been the case with many industries, large global players now tend to dominate the market. While individual national or local beer product brands may remain in production, these are often now in the ownership of large global corporations. For example, in Greece, two large global corporations hold a 90\% share of the beer market. The third largest global brewer, the Dutch corporation HeinekenNV, produces Amstel, Heineken, and Alfa beers through its Athenian Brewery subsidiary, and holds a 75\% market share. 'Denmark's Carlsberg Group, the world's fourth leading brewer (Vrellas \& Tsiotras, 2014, p31) holds 15\% market share with its Mythos brand produced by its subsidiary the Mythos Brewery. This leaves only $10 \%$ of the Greek beer market to be shared around other breweries, including local beer brewers and microbreweries. Corfu Microbrewery, a small family owned firm, is the largest of all microbreweries in Greece.

\section{Corporate Culture}

\section{Corporate history}

The Corfu Microbrewery was legally established in 2006 by Spyros Kaloudis and his son Thanasis, but the company was unable to access the funds required to set up the brewery factory due to not only the global economic crisis, but also due to the way this crisis particularly impacted on Greece, so the business proper started in 2008, with the first beer produced in 2009. Also due to this faltering start, the company has been established as two separate legal entities, 


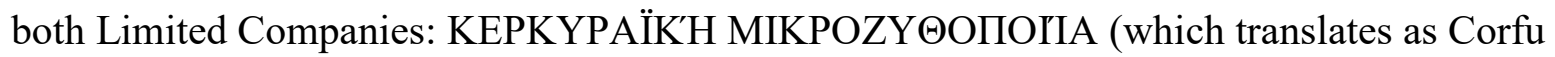
Microbrewery), and Corfu Beer (not only one of the established legal corporate forms, but also the name of one of the company's product lines.

\section{Corporate philosophy, values, mission, principles and guidelines}

The company's aim was to create beers with a local Corfiot character, targeted at tourists, local inhabitants, and to geographically close export markets in other of the seven Ionian Islands and on the Greek mainland, particularly in order to address the dominance of the Heineken and Carlsberg brands in the market, with visitors not really having the opportunity to buy an authentically 'local' Corfiot beer. While underpinning the corporate philosophy is therefore a desire to offer the market a truly authentic local craft product, the microbrewery's owner is also keen to underpin a corporate philosophy of offering a natural, fresh, living beer product to the market. Not only would this contribute to his product's differentiation against those of the mass brewers, but it also aligns with his personal philosophy of offering a product made with no preservatives, no chemicals, and, where possible, using local ingredients.

His primary goal is not simply to grow his business to increase its profitability, the goal is underpinned by a philosophy to build the company's brand and help the place within which the microbrewery is located, Arillas, a small village in the North West of Corfu. Corporate values are underpinned by being a local company, a family business, feeling a sense of belonging not only the island, but also the village, and to give back to the community. The owner is driven not only by a desire for his company to be successful but also for this success to inspire other local producers and local businesses on the island to create more local products linked to the island. 
These values appear to be shared by other senior managers. The Marketing Manager is not a family member, but he expressed similar views about the company's values as did the owner and other senior managers who are family members.

\section{Founder of the company}

Having previously worked for large global corporations such as Coca-Cola and Delta, the owner, while not previously familiar with the brewing industry, did understand the logistics of getting beverage products into the market. However, he also wanted to establish his own company in order to realise the vision of his personal philosophy.

\section{Country of origin}

The country and region of origin of the company is inherently tied not only to its own corporate identity, but also to the products it produces. Establishing the brewery in a village an hour-long drive across the mountains from the main town was also important to the owner, because he wanted to produce a local authentic Corfiot product, but also to provide good promotion for his home village. This also meant he could provide a product where profits were not repatriated to countries such as the Netherlands and Denmark, corporate homes to the large global players dominating the market.

Local pride in the brewery's local product is also evident among the brewery's senior management team. The sales manager realises the importance of having a local brand aimed at to tourists who wish to consume local products as part of their experience. 


\section{Subcultures}

No corporate subcultures were identified in this research. The company is at the smaller end of the SME spectrum. All employees work from one building. While they have designated areas of responsibility, because it is such a small company, not only do the corporate values appear to be shared among all employees, many of whom are members of the owner's family, each employee will step in to deal with tasks associated with other areas of responsibility as and when required.

\section{Corporate Strategy}

The decision to venture into near export markets on the Greek mainland and other Ionian Islands was taken specifically in order to address the issue of seasonality of the natural beers the company produces that have a shelf life of no more than around two months. When brewing started, the company was producing only around 100,000 litres of beer in a year, serving around 50 local pubs, restaurants and tavernas. In the last 5 years this production capacity has increased six-fold and the company's products are now sold in around 700 outlets. However, the company still finds it difficult to keep production supply in line with demand in the summer months, and in the winter months must seek export markets in order to flatten out the demand curve, which now account for around $20 \%$ of the company's sales.

In line with the owner's philosophy of not growing too fast, or indeed ever wanting to grow too big, the owner's son, the company's financial director, agrees with this strategy of step-by-step growth that will be less likely to compromise the quality of the products, and be more responsive to the needs of the market. 
Due to the nature of its highly seasonal main summer tourist market, the company regularly receives requests for details of where its products can be found in other countries. Growth through licensing or franchising has been discounted for the time-being. The company is still very small, does not want to over-extend itself at the risk of losing product quality and brand reputation, is still not achieving full production capacity for its current markets, and does not currently have the staff to potentially manage a licensing or franchise arrangement in foreign markets.

\section{Differentiation strategy}

The Corfu Microbrewery differentiates itself from other Greek microbreweries by producing only natural living products. Interestingly, the marketing manager believes this differentiation means that they can focus more on what their own company does than what the competition does. In terms of the headway the company is making with regard to market share by pursuing such a strategy, they understand that such a geographically bounded market such as that on their island with a declining tourist economy, the overall market is unlikely to grow, so they must ensure they grow their share of this market. Such is the local pride in Corfu Beer that the financial director has noticed that while the larger companies sometimes pay a premium to have their products promoted at point of sale, many bars do not ask this of the Corfu Microbrewery.

\section{Positioning Strategy}

Corfu Beer aims to be perceived as a quality product, rather than as a cheap brand. The bottled beers are generally slightly more expensive than the market leader brands Amstel, Heineken, Mythos and Alfa, however, on draft the lager is around the same price as Mythos. The company 
also wanted to ensure it did not position its price point too high for local people, especially as the company is local, and understands the problems facing an island in the current economic climate, where many local people are also relying on seasonal tourism employment for their annual income.

\section{Corporate Structure}

The management team comprises the owner, along with his business partner who is the head brewmaster, and the owner's son who is the company's Financial Director. The Communications Manager is the owner's niece, there are also, from outside the family, a Sales Manager and Marketing Manager. The owner's wife heads the logistics management team whose vans deliver the products.

\section{Brand structure}

Apart from the occasional production of speciality one-off ales, the company produces a small range of beers under 2 main product lines: Corfu Beer (Dark Ale Bitter, Real Ale Special, Contessa IPA and the Amorosa Weiss) and Royal Ionian (bottled Royal Ionian Pilsner, Ionian Gold - keg version, Ionian Epos, and Royal Ionian Ginger Ale). The brand name 1842 was specifically created for the company's low-alcohol ginger beer.

\section{Organisational structure}

Each of the company's managers takes overall day-to-day hands-on responsibility for their own areas of expertise. In addition to the seven members of the company's management team, 
including the workers in the brewery and bottling area, and the logistics team, the microbrewery employs 20 people overall.

\section{Corporate Design}

Corporate Visual Identity System (CVIS) and Application of CVIS

The company logo is in the form of a crest. At the top of the crest are the words 'KEPKYPAÏKH

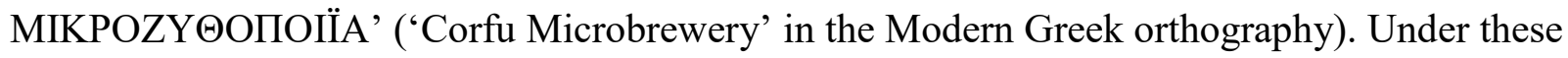
words is a crown of 5 ears of grain. Within the crest is the outline of Corfu, sharing space with the letters 'CB', Corfu Beer - words that appear in English below the crest, just under the MMVI inscription for 2006, the date the company was formed. On each side of the crest is a lion, a symbol that not only identifies with Corfu's years under Venetian rule, but also to the astrological star sign (Leo) of the company owner. The colours of the Corfu flag also reflect in the logo of the microbrewery. The logo appears on the side of the delivery vans, its bottled beer products, and on all the company's merchandising, including T-shirts, coasters, beer glasses, banners, and on all stationery and promotional literature. Indeed, the company's logo is so identified with the company's products by its tourist market, that many glasses are stolen from bars as souvenirs. The only product upon which the company logo is not prominently displayed is on the bottle of its 1842 ginger beer brand. The visual identity of this product is however connected to the place of the product's origin, using blue and yellow - the colours of the Ionian Sea and the lemon ingredient. This design encases the bottle in a protective film that also shields the contents from the effect of the sun's UV rays. The owner also believes the product's packaging and design communicates well to the product's target audience, which is a younger demographic than for its other beer products. 
The microbrewery was established in a property already owned by the company's owner. However, although not purpose-built, it is built in keeping with traditional Corfiot architecture. The brewery offers tours during the summer months, and the company's visual identity is clear from outside the building, with banners flying from flagpoles in the entrance yard, and promotional posters on the windows and also immediately inside the building where tourists gather for their pre-tour talk.

There is no company uniform as such, but members of the company, including the owner and managers, tend to wear T-shirts or Polo shirts emblazoned with the company logo when dealing with customers and other stakeholders.

\section{Behaviour}

\section{Corporate behavior}

Each village on the island in which the microbrewery is based usually holds at least one festival each year. The company donates around 10,000 litres of its beer production every year for free to local festival whose profits go to helping worthy causes.

\section{Employee and Management behavior}

The company values appear to be shared by all staff, many of whom have been with the company since its inception. There is little employee turnover, and new staff are taken on only when the business growth requires it, so far never to replace an employee who has left the company. Originally the company started with two employees working in the factory and bottling area, but every year has taken on a few more staff. It is also recognized that the brewery 
workers put in a lot of effort, and, when required to stay overtime to fill an order. The entire company is seen by all of its employees as being one large family. The owner is seen as a strong charismatic figure, who heads this family. All employees believe they can raise issues, problems, and ideas with the owner, however, it is also recognized that he has the final decision-making in all matters. He is also seen as providing inspiration to his management team.

\section{Corporate Communication}

\section{Controlled, Uncontrolled and Indirect Communication}

As a small and relatively young company, still not having reached full production capacity, the company's focus so far has been on beer production, even to the expense of other activities. With a fresh living natural product, the company cannot keep large stocks of beer, especially during the summer months, and so has to focus on production just to keep current orders filled. This is why, for example, the company's website has only recently been updated. The company also does very little advertising, preferring to promote its products via means such as engagement with local festivals, organizing promotional parties in bars, and offering brewery tours. The company also hold regular seminars for barstaff to help inform them about their products, so they may, in turn be more knowledgeable when serving their customers. Recently the Marketing Manager has overseen the production of promotional videos for its products that are communicated via YouTube and other social media. The company does not use Twitter, believing that Facebook is a better medium with which to communicate with its consumers. So far, all press stories mentioning the company and its products have been positive. The only comments written by consumers that could be perceived as negative, are very occasional cost comparisons between the cheaper brands on the market. However, this is often caused by the 
pricing strategies of some of the smaller retail outlets that sell the company's products. The company's marketing research bears this out. Consumer research that the company undertook in Athens showed that its pricing strategy is deemed very fair, and offers good value for money, and pricing is comparable with the larger global players.

The size of the company, with all employees working from the one single premises, and the hands-on nature of management activities means that members of the company communicate with each other as and when necessary. The company does not hold formal regular staff meeting for internal communications, no internal newsletter or intranet. If there is something to communicate among the entire company, the owner will call a meeting.

Being locally situated in a small village means that when the company managers are out and about, and meet local people, they tend to ask about how the company is doing, and in informal meetings even with customers, the sales manager will often go for coffee or a meal, and not talk about business, but discuss the customer's personal and social situations.

This company, a family firm at the smaller end of the SME spectrum, has a clearly defined corporate identity, focusing on being an authentically local producer of fresh, living, natural products, free from preservatives and chemicals. Corfu Microbrewery can be clearly distinguished from the larger players in its industry by an examination of its corporate philosophy, values, mission, principles and guidelines. It is this identity that makes it unique and defines both what it is and what it is not (Albert \& Whetten, 1985; Dutton \& Dukerich, 1991). 
The organisational / corporate identity and image appear to consistent, whether viewed from the inside-out, or outside-in (Dutton \& Dukerich, 1991; Walsh et al., 2009; He \& Baruch, 2010), and Corfu Microbrewery's reputation appears to be favourably perceived by all stakeholders (Lähdesmäki \& Siltaoja, 2010).

The founder of the company is a strong charismatic head of this family business, where even non-family members identify with the company as a family itself. The very local nature of the brewery's operations, with only $20 \%$ of its business done outside of its small home island, means that local residents and business owners within their distribution channels, also feel a sense of pride in the organisation and view it favourably as a local success story, and almost as their own company. The name of the company, the name of its brands and product lines, all relate to either the local island of Corfu, or to the Ionian regions, identifying the whole company as a local producer, whether that localness be Corfiot (for its home island market), Ionian (for its near neighbor island markets) or Greek (for its geographically close Greek mainland export markets). For this company, its country of origin is therefore inextricably tied to its identity, and it is this identity of being a local producer, along with its differentiation and positioning strategies of being fresh, natural, preservative-free, and competitively priced, that has allowed the company in a short space of time to increase its production six-fold, and make good headway against corporations such as Heineken and Carlsberg, that have such a large market share, even though these companies also both produce beers with Greek sounding names.

We chose to define the concept under investigation as CI (rather than OI) for a number of reasons, not least because of the lack of distinguishment between these terms found by 
Cornelissen et al. (2007), but also because a more recent view of CI that includes aspects such as 'corporate design, corporate communication and corporate behavior' along with 'corporate architecture, landscape architecture, spatial design, and corporate atmospherics' (Burghausen \& Balmer, 2014) is more encompassing, broader, and more relevant to Cl's roots in the graphic design field that contributed to the development of the related construct of corporate image. The brewery's corporate design is also inextricably linked to its country of origin, and portrays a local identity, from the company logo that reflects images symbolic of the company's island home, to the blue of the Ionian sea reflected in its ginger-beer bottle, the consistency of its identity can be seen through all of its corporate communications.

It may be that CI, for smaller firms, especially family firms, although they may focus their limited resources in areas other than strategic corporate branding and impression management techniques (Abimbola \& Kocak, 2007), becomes easier to manage due to the size of the company. In the case of Corfu Microbrewery, while recognizing that the company has to some extent focused on beer production at the expense of such matters, there does appear to be a clear strategy towards differentiation, positioning and brand building.

By basing our analysis on the seven dimensions of CI identified by Melewar and Karaosmanoglu (2006), and the way they found that each of these dimensions impacts on the other, our also findings show: The way the corporate culture has been created through the company's history, its founder and country of origin; that the corporate culture does not only impact on corporate behavior at all levels, but also that it impacts on the corporate strategy, the design CVIS and its application; that all of these elements impact on the corporate communications. All of these 
elements have created the corporate identity within its industry, and the identity of the industry has also affected the decisions taken by the company towards the creation of its distinctive identity - what it is, and what it is not, in the Greek beer market dominated by two global players.

\section{CONCLUSION}

Oliver and Roos (2007) proposed that the definitional problems regarding organisational identity rest mainly on the way the construct of "organisation" is perceived. We aimed to explore the applicability of the corporate identity (CI) construct to small and medium sized enterprises (SMEs), rather than to the larger corporate entities that have hitherto tended to be the objects of OI and CI enquiry. We believe that this paper provides an important bridge between the management literature where the concept of OI is better researched and understood, and the marketing literature where it is more common to find research defined in terms of CI. The various ways in which CI has been conceptualized, defined and deconstructed leads us to believe that such an holistic approach to an examination of CI helps inform these various literature strands that span the various management disciplines. Moreover, the silo approach to much of this previous research is not evident in practice, particularly among SMEs, where, while even in micro businesses there may be clearly defined management responsibilities, in practice, managers in SMEs may have more involvement in the day-to-day running and even strategic decision making in areas that fall outside of their specific roles.

The contribution this paper has made, therefore is in filling the gaps in knowledge about the issue of CI as it relates to entrepreneurial family-owned organisations at the smaller end of the 
SME spectrum (Abimbola, 2001; Abimbola \& Kocak, 2007), and finding that CI appears to be applicable to such organisational forms. We have also contributed to the further knowledge of CI in the brewing industry, an industry where small family firms are commonly found.

One issue that was not resolved in Melewar and Karaosmanoglu's (2006:846) research was "whether or not corporate culture was a product or determinant of corporate identity". For this relatively young, and very small company, it can be seen that its culture is definitely a determinant of its identity, with every element that contributes to its corporate culture driven by its strong charismatic owner-manager. This may be a result that is specific to family-owned SMEs, and this is something that is worthy of further investigation.

\section{REFERENCES}

Abimbola, T. (2001). Branding as a competitive strategy for demand management in SMEs. Journal of Research in Marketing \& Entrepreneurship, 3, 97-106.

Abimbola, T. \& Kocak, A. (2007). Brand, organization identity and reputation: SMEs as expressive organizations. A resources-based perspective. Qualitative Market Research: An International Journal, 10, 416-430.

Albert, S. \& Whetten, D. (1985). Organizational identity. In L. L. Cummings \& B. M. Staw (Eds.), Research in organizational behavior, 7, pp. 263-295. Greenwich, CT: JAI Press. 
Bartholmé, R.H. \& Melewar, T.C. (2009). Adding new dimensions to corporate identity management and corporate communication: exploring the sensory perspective. The Marketing Review, 9, 155-169.

Brown, T. J., P. A. Dacin, M. G. Pratt \& Whetten, D.A. (2006). Identity, intended image, construed image, and reputation: an interdisciplinary framework and suggested terminology. Journal of the Academy of Marketing Science, 34, 99-106.

Burghausen, M. \& Balmer, J.M.T. (2014). Corporate heritage identity management and the multi-modal implementation of a corporate heritage identity. Journal of Business Research, 67, 2311-2323.

Calori, R., Johnson, G. \& Sarnin, P. (1992). French and British Top Managers' Understandingof the Structure and the Dynamics of their Industries: a Cognitive Analysis and Comparison. British Journal of Management, 3, 61-78.

Cennamo, C., Berrone, P., Cruz, C. \& Gomez-Mejia, L.R. (2012). Socioemotional Wealth and Proactive Stakeholder Engagement: Why Family-Controlled Firms Care More About their Stakeholders. Entrepreneurship Theory and Practice, 36, 1153-1173.

Cornelissen, J.P., Haslam, S.A. \& Balmer, J.M.T. (2007). Social Identity, Organizational Identity and Corporate Identity: Towards an Integrated Understanding of Processes, Patternings and Products. British Journal of Management, 18, S1-S16. 
Dutton, J.E. \& Dukerich, J.M. (1991). Keeping an Eye on the Mirror: Image and Identity in Organizational Adaptation. The Academy of Management Journal, 34, 517-554.

Elsbach, K.D. \& Bhattacharya, C.B. (2001). Defining Who You Are By What You're Not; Organizational Disidentification and The National Rifle Association. Organization Science, 12, 393-413.

Geppert, M., Dörrenbächer, C. Gammelgaard. J. \& Taplin, I. (2013). Managerial Risk-taking in International Acquisitions in the Brewery Industry: Institutional and Ownership Influences Compared. British Journal of Management, 24, 316-332.

Gioia, D.A., Schultz, M. \& Corley, K. (2000). Organizational identity, image and adaptive instability. Academy of Management Review, 25, 63-81.

Harris, L.C. \& Ogbonna, E. (2007). Ownership and Control in Closely-held Family-owned Firms: An Exploration of Strategic and Operational Control. British Journal of Management, 18, $5-26$.

Hautz, J., Mayer, M.C.J. \& Stadler, C. (2013). Ownership Identity and Concentration: A Study of their Joint Impact on Corporate Diversification. British Journal of Management, 24, $102-126$. 
He, H. \& Baruch, Y. (2010). Organizational Identity and Legitimacy under Major Environmental Changes: Tales of Two UK Building Societies. British Journal of Management, 21, 44-62.

Lähdesmaäki, M. \& Siltaoja, M. (2010). Towards a Variety of Meanings - Multiple Representations of Reputation in the Small Business Context. British Journal of Management, $21,207-222$.

Melewar, T.C. \& Karaosmanoglu, E. (2006). Seven dimensions of corporate identity: A categorisation from the practitioners' perspectives. European Journal of Marketing, 40, 846-869.

Nikodemska-Wolowik, A.M. (2006). Family Enterprises - a Chance to Create a Strong Polish Business Identity. The Marketing Review, 6, 301-315.

Oliver, D. \& Roos, J. (2007). Beyond Text: Constructing Organizational Identity Multimodally. British Journal of Management, 18, 342-358.

Otubanjo, O. (2011). Practitioner conceptualisations of Corporate Identity, 1945-2010: review and analysis. The Marketing Review, 11, 263-279.

Otubanjo, O. \& Amujo, O.C. (2012). A holistic corporate identity communications process. The Marketing Review, 12, 403-417. 
Otubanjo, O. \& Chen, C-C. (2013). A functional perspective to the meaning of corporate reputation. The Marketing Review, 13, 329-345.

Pitta, D.A. \& Scherr, B.G. (2009). The product strategy for seasonal products. Journal of Product \& Brand Management, 18, 152-153.

Ullrich, J., Wieseke, J., Christ, O., Schulze, M. \& van Dick, R. (2007). The Identity-Matching Principle: Corporate and Organizational Identification in a Franchising System. British Journal of Management, 18, S29-S44.

Veldman, J. (2013). Politics of the Corporation. British Journal of Management, 24, S18-S30.

Vrellas, C. G. \& Tsiotras, G. D. (2014). Operational Excellence in the Greek Brewing Industry. Global Business and Organisational Excellence, 33, 31-38.

Walsh, G., Mitchell, V-W, Jackson, P.R. \& Beatty, S.E. (2009). Examining the Antecedents and Consequences of Corporate Reputation: A Customer Perspective. British Journal of Management, 20, 187-203. 